\title{
Weathering, structure and in situ stress in residual soils
}

\author{
P. R. VAUGHAN and C. Y. KWAN (1984). Géotechnique 34, No. 1, 43-59
}

\section{Mr T. I. Gamon and Mr C. K. Wu, Freeman Fox (Far East) Ltd \\ It is not clear from the Paper whether the} Authors carried out additional laboratory testing on residual soils, or whether the hypothesis was developed theoretically and its validity checked by comparison with existing published data. Most of the data on soil properties is based on the work of Lumb (1962) and Baynes \& Dearman $(1978 a, 1978 b)$ and it is assumed that the theory is therefore applicable only to in situ weathered granites.

The Authors comment that 'few attempts have been made to relate degree of weathering directly to engineering properties' (p. 44). The degree of decomposition $X_{\mathrm{d}}$, proposed by Lumb (1962), and adopted by the Authors, is determined by separating the mineral grains larger than approximately $0.1 \mathrm{~mm}$ under a microscope. The original quartz content is then assumed. This method is considered to be too tedious and time consuming to be of practical use. The separation of the wcathered material into specific 'weathering grades' by diagnostic features such as material strength, presence of relict texture and slakeability (Gamon, 1983; Hencher \& Martin, 1982) is generally found to be adequate for most engineering applications. It has been found that each of the weathering grades is characterized by a limited range of engineering properties (Geotechnical Control Office, 1982), and that by determining the percentage of each grade within a weathered profile the engineering behaviour of the weathered mass can be established. The clay content of $34 \%$ for $X_{d}=1$ ( $p$. 56 ) is not unreasonably high for the residual soil grade of material (Lumb, 1962, Fig. 5(a)).

Granite weathering initiates from the surface and extends along discontinuities. The removal of overburden at the surface during erosion causes a stress imbalance in the rock which is locked in as residual stress (Nichols, 1975; Sav- age, 1978). The release of these stresses at the time of weathering causes the development of a macrofabric perpendicular to the direction of stress relief. The shear strength of the weathered material parallel to the macrofabric is generally lower than that for intact material. The soil properties are therefore influenced by both the stress history and weathering acting together rather than independently (p. 43).

It is not clear what modifications to the theory would be necessary to cater for the heterogeneous nature of the material encountered in a typical weathered profile, or whether there are any practical applications of this theory.

\section{REFERENCES}

Baynes, F. J. \& Dearman, W. R. (1978a). The relationship between the microfabric and the engineering properties of weathered granite. Bull. Int. Ass. Engng Geol., No. 18, 191-197.

Baynes, F. J. \& Dearman, W. R. (1978b). The microfabric of a chemically weathcred granitc. Bull. Int. Ass. Engng Geol., No. 18, 91-100.

Gamon, T. I. (1983). A comparison of existing schemes for the engineering description and clas sification of weathered rocks in Hong Kong. Bull. Int. Ass. Engng Geol., No. 28, 225-232.

Geotechnical Control Office (1982). Mid levels study report on geology, hydrology and soil properties. Public Works Department, HM Government, Hong Kong, pp. 264.

Hencher, S. R. \& Martin, R. P. (1982). The description and classification of weathered rocks in Hong Kong for engineering purposes. Proc. 7 th Southeast Asian Geotech. Conf., Hong Kong 1, 125-143.

Lumb, P. (1962). The properties of decomposed granite. Géotechnique 12, No. 3, 226-243.

Nichols, T. C., Jr. (1975). Deformations associated with relaxation of residual stresses in a sample of Barre Granite from Vermont. US Geological Survey Protessional Paper 875, pp. 32.

Savage, W. Z. (1978). The development of residual stresses in cooling rock bodies. 